\title{
Time- and population-dependent genetic patterns underlie bovine milk somatic cell count
}

\author{
Asha M. Miles ${ }^{1}$ (i) and Heather J. Huson ${ }^{2}$ (i) \\ Department of Animal Science, Cornell University, Ithaca, NY 14853
}

\begin{abstract}
The objective of this study was to determine whether genetic regulation of bovine milk somatic cell count (SCC) varied throughout the course of an individual lactation and to identify quantitative trait loci (QTL) that may differentiate populations of chronically mastitic and robustly healthy cows. Milk SCC has long been a proxy for clinical mastitis diagnosis in management and genetic improvement strategies to control the disease. Cows $(\mathrm{n}=471)$ were genotyped on the Illumina BovineHD 777K BeadChip (Illumina Inc., San Diego, CA), and composite milk samples were collected for SCC at 0-1 d in milk (DIM), 3-5 DIM, 10-14 DIM, 90-110 DIM, and 210-230 DIM, with each time span representing key physiological transitions for the cow. Median lactation somatic cell score (SCS) and area under the SCS curve were calculated from farm test data. A total of 8 genome-wide associations were performed and 167 SNP spanning the genome were significantly associated (false discovery rate $<0.05$ ). Of these associated regions, 27 of 48 associated QTL were novel for clinical mastitis or SCC. The linkage disequilibrium block surrounding the associated QTL or a 1-Mb window in the absence of linkage disequilibrium was interrogated for candidate genes, and many of those identified were related to multiple arms of the immune system, including toll-like receptor signaling, macrophage activation, B-cell maturation, T-cell recruitment, and the complement pathway. These genes included EXOC4, BAMBI, ITSN2, IL34, FCN3, CD8A, and CD8B. In addition, we identified populations of robustly healthy (SCS $\leq 4$ from 10-14 DIM until study end), chronically mastitic (SCS >4 from 10-14 DIM until study end), and average cows with fluctuating SCS, and calculated fixation indices to identify regions of the genome differentiating these 3 populations. A total of 12 SNP were identified

Received February 6, 2020.

Accepted April 21, 2020.

${ }^{1}$ Current address: Department of Animal Science, The Pennsylvania State University, University Park, PA 16802.

${ }^{2}$ Corresponding author: hjh3@cornell.edu
\end{abstract}

that showed moderate allelic differentiation (Wright's F statistic, $\mathrm{F}_{\mathrm{ST}} \geq 0.4$ ) between the "chronic," "healthy," and "average" populations of cows. Candidate genes in the region surrounding differentiated QTL were related to cell signaling and immune response, such as JAKMIP1 and MADCAM1. The wide range of significantly associated QTL spanning the genome and the diversity of gene functions reinforces that mastitis is a complex trait and suggests that selection based on lactation stage-specific SCS rather than a generalized score may lead to greater success in breeding mastitis-resistant cows.

Key words: genome-wide association, mastitis, somatic cell score, single nucleotide polymorphism

\section{INTRODUCTION}

Mastitis, a condition characterized by inflamed mammary tissue and the costliest disease facing US dairy producers, can be attributed to problems with herd and farm management, milking management, the milking machine, and the cow itself (Mein et al., 2004; Rollin et al., 2015). In 1994, milk SCC, a common proxy for mastitis diagnosis, was added to national bovine genetic evaluations specifically to address the impact of elevated SCC on cow production and health (Schutz, 1994). Although the genetic evaluation of dairy cattle has long been used to improve production and health traits, improvements by linkage-based marker-assisted selection have been hindered by the small proportion of genetic variation explained by each marker in regards to complex traits, as well as the high costs associated with marker validation (Soller, 1994; Andersson, 2001; Misztal, 2006). In addition, the use of deregressed breeding values for bulls not directly exhibiting the phenotype (mastitis), the lack of standardized reporting in the United States, and the use of population and lactation-average data in trait definition potentially introduce bias to mastitis phenotypes and their genetic associations (Council on Dairy Cattle Breeding, 2014). As genotyping technologies become increasingly affordable, more studies have emerged utilizing SNP chips, genotype imputation, RNA-seq, and whole-genome se- 
quence data (Biffani et al., 2017; Fang et al., 2017; Cai et al., 2018). To date, no GWAS has been conducted utilizing high-density cow genotypes and direct longitudinal SCC phenotyping on the same animals.

Although SCC is a well-established proxy for mastitis diagnosis, lactation-average SCS and deregressed breeding values are generalized phenotypes that may not detect the specific mechanisms underlying the recruitment of somatic cells to the udder. Inflammatory states postpartum have been well documented, and numerous studies have established that inflammatory responses are elevated following parturition, given the stresses of lactogenesis, uterine involution, and changes in metabolic state, even in the absence of disease (Bionaz et al., 2007; Graugnard et al., 2012; Akbar et al., 2015). Elevated milk SCC due to postpartum inflammation may skew lactation-average data upward, resulting in an inaccurate characterization of mastitis susceptibility. The objective of this study was to longitudinally characterize SCC in a cohort of cows and use highdensity genotype data to examine the genetics driving elevated SCC across different stages of lactation, and to assess the genetic differentiation among populations of chronically elevated and robustly healthy cows. This study was designed specifically to address the limitations of using lactation-average SCS for genomic selection of mastitis-resistant dairy cattle, given that there are nonpathological reasons for udder inflammation and that SCC is not exclusively an indicator of disease.

\section{MATERIALS AND METHODS}

Approval from the Cornell University Institutional Animal Care and Use Committee (Protocol \#20140121) and signed owner consent were obtained before commencement of the study.

\section{Phenotyping}

From June 2015 to July 2016, a convenience sample of 523 dairy cows from 2 farms in upstate New York were enrolled in a prospective cohort study; that is, any cows that calved within $24 \mathrm{~h}$ of farm visits were candidates for inclusion in the study. Sampling involved 6 composite milk collections representing key physiological time points in lactation as previously described (Miles et al., 2019). The physiological conditions sampled for were parturition (0-1 DIM), baseline milk after clearance of colostrum (3-5 DIM), peak mastitis incidence and negative energy balance (10-14 DIM), return to neutral or positive energy balance (50-60 DIM), peak production and early pregnancy (90-110 DIM), and mid to late lactation (210-230 DIM). A California Mastitis Test (CMT) was used to assign a binary score to colostrum samples (0-1 DIM); positive if the CMT solution reacted to create distinct thickening of the sample or negative if the sample remained liquid (Schalm and Noorlander, 1957). All remaining milk samples were outsourced to a milk laboratory for SCC by flow cytometry as previously described (Fossomatic, Dairy One, Ithaca, NY; Miles et al., 2019). Both farms participated in monthly DHI testing, and milk test data from the study period were pulled from herd management software (DairyComp 305, Valley Agricultural Software, Tulare, CA). Farm milk test data were generated by the same laboratory that processed the researcher-collected samples. All SCC data were logarithmically transformed to a linear SCS using the following equation:

$$
S C S=\frac{\ln \left(\frac{S C C}{10^{5}}\right)}{\ln (2)}+3
$$

in R Studio version 3.6.0 (R Core Team, 2019). Median SCS and area under the SCS curve (AUC) were calculated from the farm milk test data.

\section{Genotyping and Quality Control}

Genomic DNA was extracted from whole blood taken from the coccygeal vessel, collected in $10-\mathrm{mL} \mathrm{K}_{2}$ EDTA anticoagulant Vacutainers (Becton, Dickinson, \& Company, Franklin Lakes, NJ), and kept at $4^{\circ} \mathrm{C}$ if DNA was extracted within $1 \mathrm{wk}$ or at $-20^{\circ} \mathrm{C}$ for long-term storage. Extractions were performed according to the Gentra Puregene Blood Kit protocol (Gentra Systems Inc., Minneapolis, MN) using laboratory-made buffers. A total of 471 cows were submitted for SNP genotyping on the Illumina BovineHD 777K BeadChip (Illumina Inc., San Diego, CA) by GeneSeek (Neogen Genomics, Lincoln, NE). Quality assurance measures filtered out samples with SNP and individual call rate $<0.9$, minor allele frequency $(\mathbf{M A F})<0.05$, and allele number $>2$. The relatedness of all pairs of individuals was assessed via identity-by-descent (IBD) estimates imputed from identity-by-state distances calculated with genotype data as described in Purcell et al. (2007). Individuals with IBD estimates $\geq 0.9$, demonstrating significant relatedness, were removed. After all quality control filtering was applied, 458 cows with 581,663 SNP remained for analysis.

\section{Population Analyses}

To identify distinct populations of cows, SCS at 10-14 DIM was plotted against SCS at 50-60 DIM (Figure 
1A) and quadrants drawn at a threshold of SCS $=4$ ( $\mathrm{SCC}=200,000$ cells $/ \mathrm{mL}$ ), a well-established threshold at which intramammary infection is likely present (McDermott et al., 1982; Dohoo and Leslie, 1991; Schepers et al., 1997). Cows with SCS $\leq 4$ at both 10-14 DIM and 50-60 DIM were designated "healthy" (green squares in Figure 1), those with SCS $\leq 4$ 10-14 DIM but SCS $>4$ at 50-60 DIM were designated "new cases" (black circles), those with SCS $>4$ at 10-14 DIM but SCS $\leq 4$ at 50-60 DIM were labeled "cures" (blue stars), and cows with SCS $>4$ at both time points were labeled "chronic" (red triangles). The progression of these 4 groups of cows over their lactation was tracked by plotting SCS at 50-60 DIM against SCS at 90-110 DIM (Figure 1B), and SCS at 90-110 DIM against SCS at 210-230 DIM (Figure 1C). Populations were defined as cows that remained in the "healthy" quadrant the entire study period (solid green squares, $\mathrm{n}=239$ ), those with "chronic" elevated SCC throughout the study period (solid red triangles, $\mathrm{n}=12$ ), and "average" cows whose SCC fluctuated across quadrants during the study $(\mathrm{n}=168)$. Wright's F Statistic $\left(\mathbf{F}_{\mathbf{S T}}\right)$ by marker was calculated to measure the genetic divergence between the subpopulations of "healthy" and "average," "healthy and "chronic," and "average" and "chronic," with 0 representing no allelic divergence between populations and values up to 1 suggesting increasing population differentiation (Weir and Cockerham, 1984). Golden Helix SNP and Variation Suite (2017) computes $\mathrm{F}_{\mathrm{ST}}$ using the equation $\hat{\theta}=\frac{a}{a+b+c}$, where $a$ is the variance component between subpopulations, $b$ is the variance component within subpopulations and between individuals, and $c$ is the sample-based population estimate of the variance component between gametes within individuals, as given by Weir and Cockerham (1984). Any SNP with $\mathrm{F}_{\mathrm{ST}} \geq 0.4$ was considered moderately differentiated, given the high prevalence of inbreeding within Holstein cattle, and the surrounding regions were investigated for candidate genes as described below (Forutan et al., 2018).

\section{Genome-Wide Association}

Efficient mixed model linear analysis (EMMAX) models were used to allow the inclusion of the IBD matrix to correct for any population structure in Golden Helix SNP and Variation Suite software version 8.8.3 (Kang et al., 2010). The mixed model EMMAX uses the following general equation: $\mathbf{y}=\mathbf{X} \boldsymbol{\beta}+\mathbf{Z} u+\mathbf{e}$, where $\mathbf{y}$ is an $n \times 1$ vector of observed phenotypes; $\mathbf{X}$ is an $n \times f$ matrix of fixed effects, including mean, SNP, and other covariates; $\boldsymbol{\beta}$ is a $f \times 1$ vector representing
A

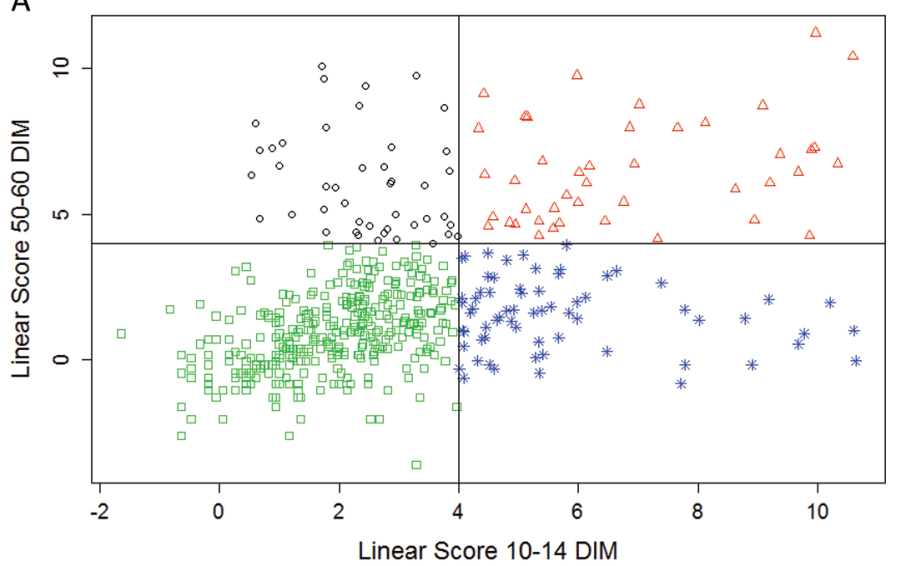

B

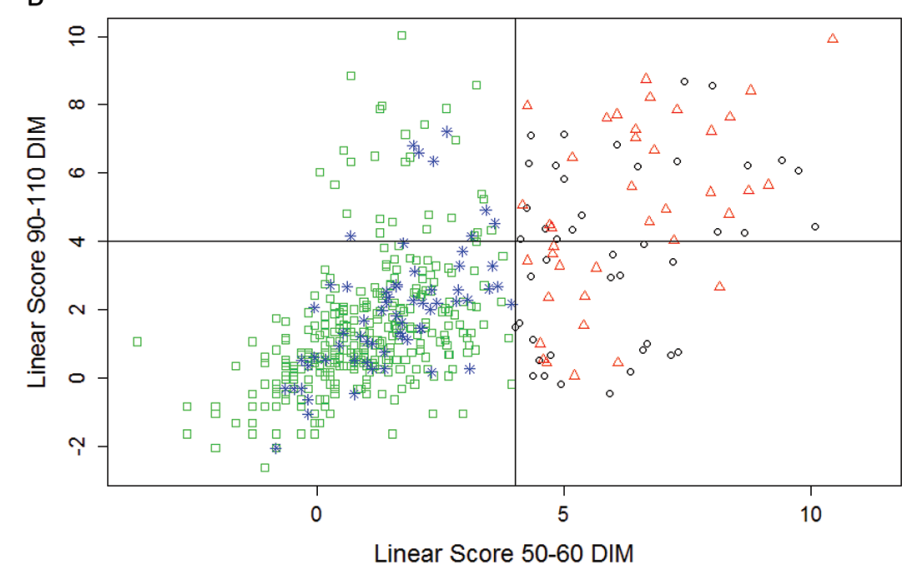

C

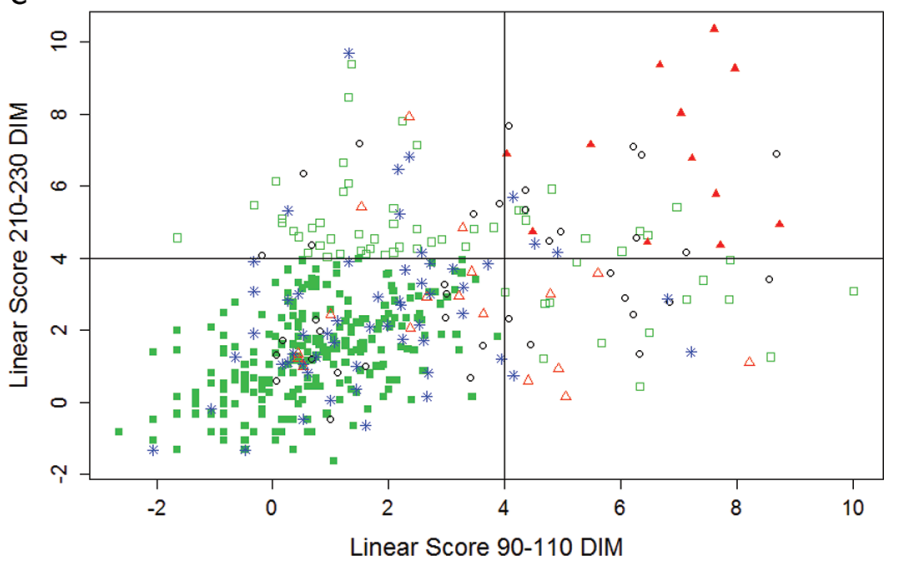

Figure 1. Overview of SCS-based population stratification. Linear SCS at (A) 10 to 14 DIM plotted against 50 to 60 DIM, (B) 50 to 60 DIM plotted against 90 to 110 DIM, and (C) 90 to 110 DIM plotted against 210 to 230 DIM. Cows with SCS $<4$ at 10 to 14 DIM and 50 to 60 DIM are designated with an open green square, cows with SCS $<4$ at 10 to 14 DIM and $\geq 4$ at 50 to 60 DIM are designated with an open black circle, cows with SCS $\geq 4$ at 10 to 14 DIM and 50 to 60 DIM are designated with an open red triangle, and cows with SCS $\geq 4$ at 10 to 14 DIM but $<4$ at 50 to 60 DIM are designated with a blue star. Solid green squares represent cows that had SCS $<4$ at all 4 time points; solid red triangles represent cows that had SCS $\geq 4$ at all 4 time points. 
the coefficient of the fixed effects (farm and parity); $\mathbf{Z}$ is an $n \times t$ matrix relating the instances of the random effect to the phenotypes (CMT or SCS at specific lactation stages); $u$ is the unknown random effect of the mixed model with $\operatorname{Var}(u)=\sigma_{g}^{2} \mathbf{K}$, where $\sigma_{g}^{2}$ is the genetic component of variance; $\mathbf{K}$ is the kinship matrix inferred from the genotype; and $\mathbf{e}$ is an $n \times n$ matrix of residual effect that cannot be explained by the variables in the model (Kang et al., 2010). Variance components are calculated for the entire association analysis in EMMAX given that the effect for each SNP is relatively small. Additive, dominant, and recessive inheritance models were considered along with the variables of farm, parity, and milk yield given their potential confounding effects on traits of interest. To identify QTL associated with elevated SCC and potential subclinical mastitis at time of calving, a case-control GWAS using the binary CMT score at $0-1$ DIM was performed. To determine the influence of lactation stage on elevated SCC events, 5 genome-wide associations (GWA) were performed for the quantitative trait of SCS at 3-5 DIM, 10-14 DIM, 50-60 DIM, 90-110 DIM, and 210-230 DIM. To establish a point of comparison for these lactation stage analyses, a GWA for the traditional phenotype of average lactation SCS was performed. To account for variation in SCS not represented by a median score, a GWA was performed for SCS AUC. Lactation length was included as a covariate in all genome-wide associations for total lactation traits (median SCS, AUC) to address the influence of varying time at risk on longitudinal SCS measures. Farm-culled cows before the study end-point were not censored in our analysis to allow for genetic investigation of animals that may experience disease susceptibility, resulting in different sample sizes per SCS time point (Table 3). $P$-values were adjusted for multiple testing using a Bonferroni correction and false discovery rate (FDR) threshold of 0.05. Estimated SNP effects were generated as follows:

$$
p v e=\frac{m r s s_{h 0}-m r s s_{k}}{m r s s_{h 0}},
$$

where pve is the proportion of variance explained, $m r s s_{h 0}$ is the Mahalanobis root sum of squares under the null hypothesis of no association, and $m r s s_{k}$ is the actual Mahalanobis root sum of squares for marker $k$ (Segura et al., 2012).

\section{Model Selection and Candidate Gene Investigation}

A genomic inflation factor lambda (median observed $P$-value divided by median expected $P$-value) and quantile-quantile (Q-Q) plots of $\log _{10}$ (expected $P$-values) against $\log _{10}$ (observed $P$-values) were used to select the most appropriate models for each trait. The pseudo-heritabilities of each trait were calculated as follows:

$$
p h_{j}=\widehat{\sigma_{g}^{2}} / \operatorname{Var}(y)
$$

where $\widehat{\sigma_{g}^{2}}$ is the genetic component of variance, and $\operatorname{Var}(y)$ is given by $\widehat{\sigma_{g}^{2}}+\widehat{\sigma_{e}^{2}}$, the sum of the genetic $(g)$ and error $(e)$ components of variance (SNP and Variation Suite, 2017). Regions with SNP passing FDR were interrogated for candidate genes, and any gene in linkage disequilibrium (LD) with an associated marker $\left(\mathrm{r}^{2}\right.$ $\geq 0.8$ ), or in a $500-k b$ region upstream or downstream range of said marker if LD was not present, was identified using the National Center for Biotechnology Information RefSeq database (O'Leary et al., 2016). All genome coordinates given use the most recent bovine genome assembly ARS_UCD 1.2 (https://www.ncbi.nlm .nih.gov/assembly/GCF_002263795.1/).

\section{RESULTS}

After all quality assurance measures were applied, 458 cows with 581,663 SNP remained for analysis. Descriptive statistics for SCS phenotypes are reported in Table 1. A comprehensive list of differentiated or significantly associated markers, their positions, and surrounding candidate genes can be found in Supplemental Tables S1 and S2, respectively (https://doi.org/ 10.3168/jds.2020-18322). The functions of biologically relevant candidate genes and the estimated effects of each associated SNP are summarized in Supplemental Tables S3 and S4, respectively (https://doi.org/10 .3168/jds.2020-18322).

\section{Population Analyses}

Plots of $\mathrm{F}_{\mathrm{ST}}$ by marker comparing different populations is shown in Figure 2. There was no apparent allelic differentiation between average and healthy populations (Figure 2A). Twelve SNP indicated divergence $\left(\mathrm{F}_{\mathrm{ST}} \geq 0.4\right)$ between average and chronic populations on BTA 4, 6, and 7 (Figure 2B). In a comparison of healthy and chronic populations, 3 SNP were differentiated $\left(\mathrm{F}_{\mathrm{ST}} \geq 0.4\right)$ on BTA 4 and 5 (Figure 2C). All 9 moderately differentiated SNPs on BTA 4 resided in an LD block including 2 SNP located at BTA 4:18655887 and 18669066, which were identified in both the aver- 


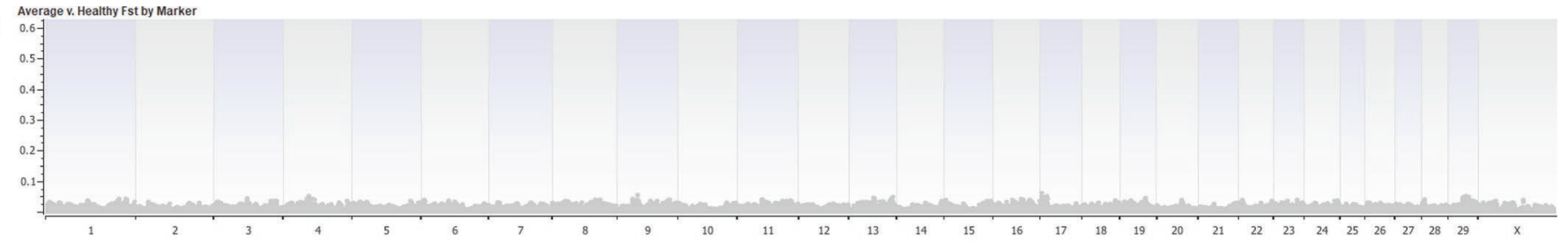

B

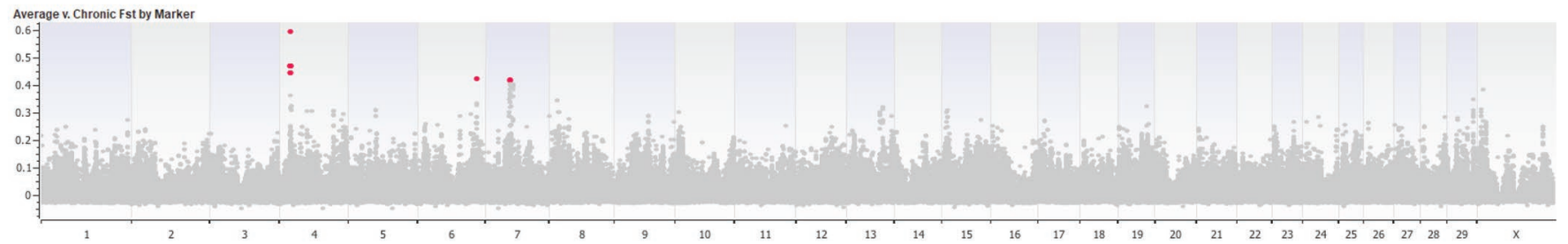

C Healthy v. Chronic Fst by Marker

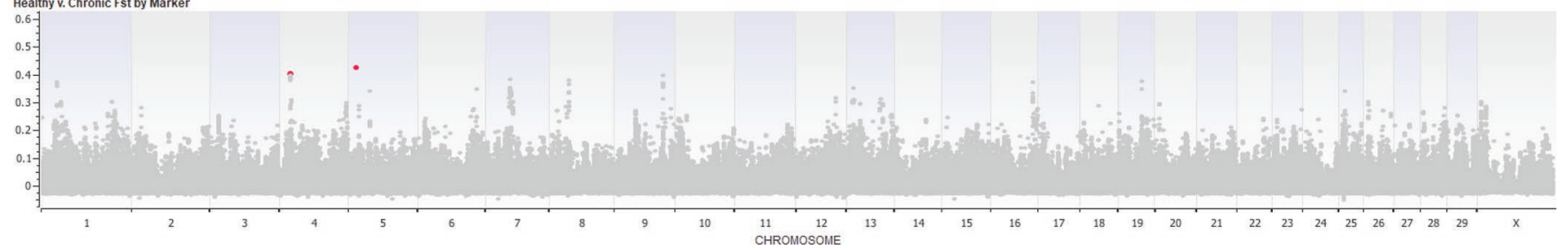

Figure 2. Wright's F Statistic $\left(\mathrm{F}_{\mathrm{ST}}\right)$ by marker comparing $(\mathrm{A})$ average and healthy, $(\mathrm{B})$ average and chronic, and $(\mathrm{C})$ healthy and chronic populations; SNP with moderate allelic differentiation $\left(\mathrm{F}_{\mathrm{ST}} \geq 4\right)$ are indicated in red.

age and healthy cow comparisons with chronic cows (Figure 3). For each SNP, chromosome, position, major and minor alleles, and MAF stratified by healthy, average, and chronic populations are summarized in Table 2 .

\section{Genome-Wide Associations}

Final models selected are summarized in Table 3 with respective Manhattan and Q-Q plots shown in Figure 4 and Supplemental Figure S1 (https://doi.org/10 .3168/jds.2020-18322). A dominant inheritance model with farm and parity covariates significantly associated 8 SNP (FDR <0.05), with an average SNP effect of 0.058 with CMT score at time of calving on BTA 4 and 13 (Figure 4A). Recessive inheritance models with no covariates identified QTL associated with SCS at different stages in lactation spanning the genome. Although models including the potentially confounding fixed effects of farm and parity were considered, they had a higher genomic inflation factor (pseudo-lambda) and there was no appreciable difference between Q-Q plots for models with and without covariates. A total of 23 SNP were significantly associated with SCS at 10-14 DIM on BTA 3, 5, 6, 11, and 29 (Figure 4C); 8 SNP were significantly associated with SCS at 50-60 DIM on BTA 1, 3, 4, and 26 (Figure 4D); and 103 SNP were significantly associated with SCS at 210-230 DIM on 10 chromosomes spanning the genome (Figure $4 \mathrm{~F}$ ). The average SNP effect of the significantly associated SNP for these SCS time points was 0.059, 0.058 , and 0.056 respectively. There were no significant associations with 3-5 DIM or 90-110 DIM (Figure $4 \mathrm{~B}$ and $\mathrm{E}$, respectively). Recessive inheritance models

Table 1. Descriptive statistics of each SCS phenotype: mean, median, variance, interquartile range (IQR), and sample size (n) across all cows are reported

\begin{tabular}{lcrrrc}
\hline Item & $\mathrm{n}$ & Mean & Median & Variance & IQR \\
\hline Area under lactation SCS curve & 451 & 577.2 & 512.4 & 179,557 & 574.6 \\
Lactation median SCS & 454 & 2.2 & 1.8 & 2.8 & 2 \\
SCS at 3-5 DIM & 454 & 4.1 & 3.7 & 3.5 & 2.1 \\
SCS at 10-14 DIM & 451 & 2.9 & 2.5 & 6.9 & 2.4 \\
SCS at 50-60 DIM & 448 & 1.9 & 1.4 & 5.6 & 2.5 \\
SCS at 90-110 DIM & 438 & 1.9 & 1.3 & 4.5 & 2.8 \\
SCS at 210-230 DIM & 418 & 2.3 & 1.9 & \\
\hline
\end{tabular}


A Average v, Chronic Fst by Marker

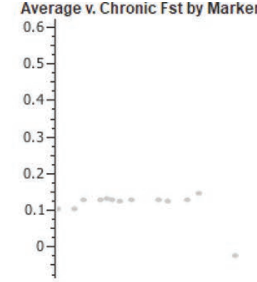

B Healthy v. Chronic Fst by Marker

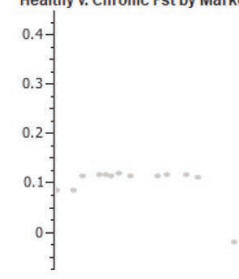

C Linkage Disequilibrium

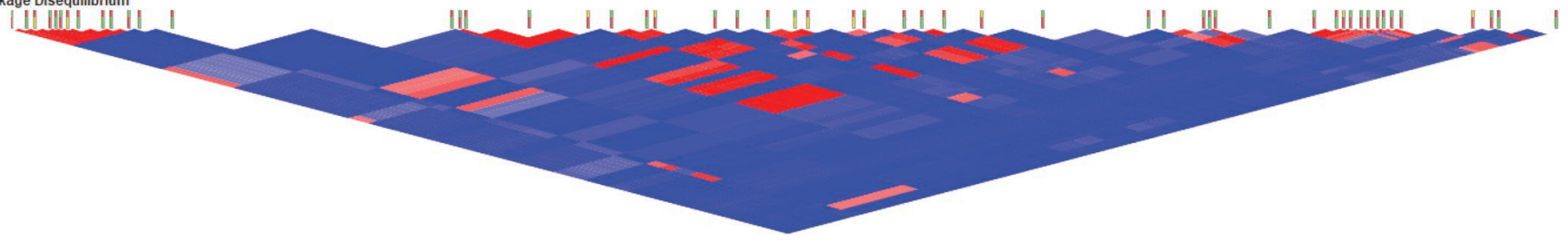

Figure 3. Wright's F Statistic $\left(\mathrm{F}_{\mathrm{ST}}\right)$ by marker on BTA 4 comparing $(\mathrm{A})$ average and chronic populations, (B) healthy and chronic populations, and $(\mathrm{C})$ linkage disequilibrium in this region; SNP with moderate allelic differentiation $\left(\mathrm{F}_{\mathrm{ST}} \geq 4\right)$ are indicated in red.

with covariates of parity, farm, and lactation length significantly associated 25 SNP with median SCS on 12 chromosomes across the genome (Figure 4G). Single nucleotide polymorphisms associated with median SCS had the lowest average SNP effect at 0.050. No SNPs were significantly associated with AUC.

\section{DISCUSSION}

\section{Population Analyses}

In our comparison of healthy and average populations, the low $\mathrm{F}_{\mathrm{ST}}$ by marker values suggested that the

Table 2. Marker-based $\mathrm{F}_{\mathrm{ST}}$ (Wright's F statistic) analysis identified markers differentiating Holstein cow populations based on their SCS ${ }^{1}$

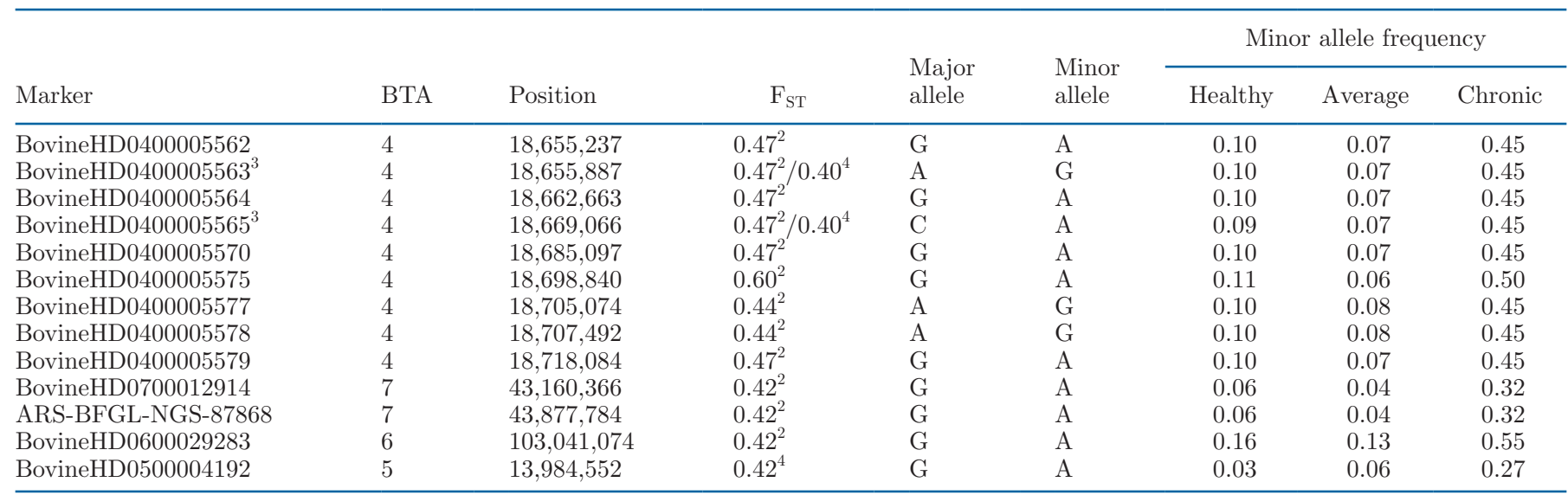

${ }^{1}$ Healthy $=$ SCS $\leq 4$ from 10 to 14 DIM until study end; average = cows with fluctuating SCS during study period; chronic $=$ SCS $>4$ from 10 to 14 DIM until study end.

${ }^{2}$ Moderately differentiated SNPs $\left(\mathrm{F}_{\mathrm{ST}}>0.4\right)$ between average and chronic populations.

${ }^{3} \mathrm{SNPs}$ differentiating chronic cows from both healthy and average populations.

${ }^{4}$ Moderately differentiated SNPs $\left(\mathrm{F}_{\mathrm{ST}}>0.4\right)$ between healthy and chronic populations. 
Table 3. Summary of genome-wide association models selected, including sample size (n), model type, inheritance patterns, quality control measures, trait heritabilities, and total number of significantly associated SNP

\begin{tabular}{|c|c|c|c|c|c|c|c|}
\hline SCS trait & $\mathrm{n}$ & Model type & Inheritance & $\begin{array}{l}\text { Pseudo- } \\
\text { lambda }^{1}\end{array}$ & $\begin{array}{l}\text { Pseudo- } \\
\text { heritability }\end{array}$ & $\mathrm{FDR}^{2}$ & Bonferroni $^{2}$ \\
\hline $\mathrm{CMT}^{3}$ & 454 & Case-control & Dominant & 1.00 & 0.40 & 9 & 0 \\
\hline 50-60 DIM & 448 & Linear & Recessive & 1.00 & 0.31 & 8 & 0 \\
\hline 90-110 DIM & 438 & Linear & Recessive & 0.99 & 0.43 & 0 & 0 \\
\hline 210-230 DIM & 418 & Linear & Recessive & 0.99 & 0.35 & 106 & 24 \\
\hline
\end{tabular}

${ }^{1}$ Genomic inflation factor for model quality control; quantile-quantile plots in Supplemental Figure S1 (https://doi.org/10.3168/jds.2020-18322).

${ }^{2}$ Number of SNP associations passing either Bonferroni or false discovery rate (FDR) multiple testing corrections at $P<0.05$.

${ }^{3}$ California Mastitis Test.

${ }^{4}$ Area under the curve.

genetic difference is small between cows with consistently low SCC and cows that experience fluctuations in SCC as their lactation progresses. However, $\mathrm{F}_{\mathrm{ST}}$ by marker analysis revealed that genomic regions differentiated chronic cows from both average and healthy cows, suggesting that cows that chronically experience elevated SCC are genetically different from cows with more consistently low milk SCC. Of particular interest is the QTL identified on BTA 4, which indicated differentiation of the chronic population from all other cows (Figure 3). The breaks in this LD block suggest this region may be a recombination site; only 2 of the 9 markers differentiating chronic and average cows also differentiated chronic and healthy cows, but LD suggests they are inherited together in the study population. An overlapping QTL has previously been mapped for milk SCS in a large Holstein study using microsatellite data and a granddaughter design (Zhang et al., 1998), reinforcing the relevance of these SNP markers for use in selecting for mastitis-resistant cows. In contrast, the SNP at BTA 6:103041074 has not been previously associated with mastitis-related traits, whereas the QTL identified on BTA 7 differentiating average and chronic cows overlaps with QTL previously mapped for milk SCS in German Holsteins (Kühn et al., 2003). Other QTL in this region have been mapped for milking speed and milk yield, complex traits that are likely polygenic and pleiotropic and have been associated with mastitis risk (Boichard et al., 2003; Schrooten et al., 2004; Japertiene et al., 2007; Marete et al., 2018). We propose that these differentiated markers are candidates for inclusion in selection indices for mastitis-resistant cows, given their prior association with mastitis-related traits through QTL mapping and the immune-related functions of the candidate genes within which these SNP reside (Supplemental Table S3; https://doi.org/ 10.3168/jds.2020-18322). However, selection strategies based on the QTL on BTA 7 should be made with caution, given that it has been mapped for milk yield and milking speed, and further investigation is required to ensure that selection for mastitis resistance is not antagonistic to milk yield, and vice versa.

\section{Genome-Wide Associations}

To assess the genetics underlying postpartum elevated SCC, a case-control GWA for CMT score at 0-1 DIM (negative $\mathrm{n}=398$, positive $\mathrm{n}=125$ ) was performed, and SNP were significantly associated on BTA 4 and 13 , the former of which has not been previously mapped for any health traits (Figure 4a). A significantly associated SNP located at BTA 13:35930715 overlaps with a previously mapped QTL for SCS and milk yield in Danish Holsteins, suggesting that this QTL may have pleiotropic effects related to milk production traits (Lund et al., 2008). We previously associated positive CMT scores at time of calving with increased odds of experiencing an elevated SCC event, suggesting that not only may CMT score at time of calving be a useful measure for selective management of high-risk cows, but that these associated markers are strong candidates for inclusion in health trait indices for genomic selection (Miles et al., 2019). However, the potential pleiotropy of the associated QTL on BTA 13 makes it difficult to use in genomic selection because of the potentially inverse relationships of SCS and milk yield. Candidate genes investigated had functions related to both innate and adaptive immunity (Supplemental Table S3; https://doi.org/10.3168/jds.2020-18322). For example, the associated marker at BTA 4:97507560 lies directly within exocyst complex component 4 (EXOC4), a protein complex implicated in mechanisms of host defense due to its role in long-range cell signaling and phagosome maturation (Martin-Urdiroz et al., 2016). Similarly, candidate genes near the associated SNP at BTA 13:35930715 include lysozyme like 1 (LYZL1), an 

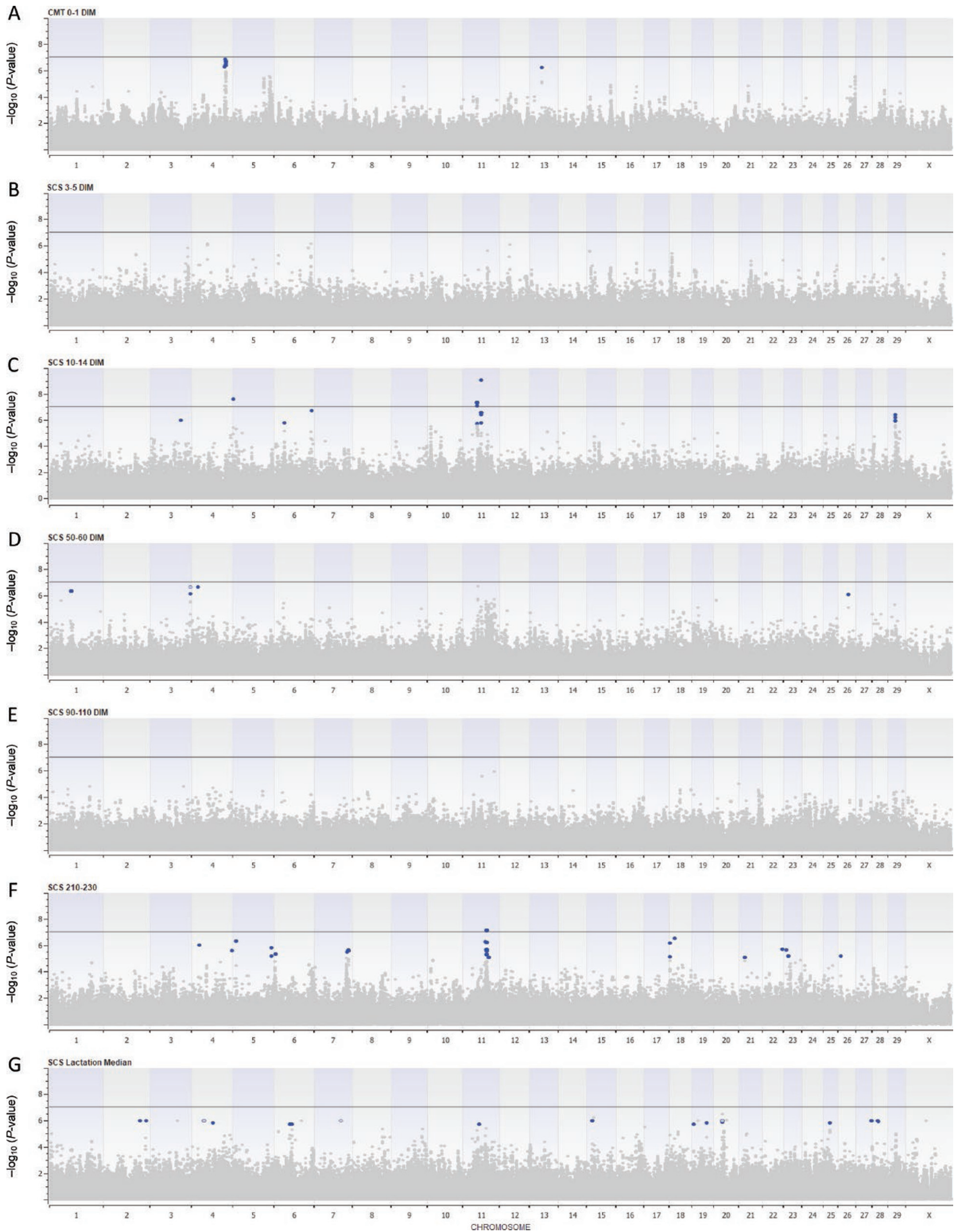

Figure 4. Manhattan plots showing associated SNPs at (A) 0-1 DIM, (B) 3-5 DIM, (C) 10-14 DIM, (D) 50-60 DIM, (E) 90-110 DIM, (F) 210-230 DIM, and (G) median SCS for entire lactation. Significantly associated SNPs (false discovery rate $<0.05)$ are indicated in blue. The black line indicates the Bonferroni multiple correction threshold. CMT = California Mastitis Test. 
antimicrobial protein, and BMP and activin membrane bound inhibitor $(B A M B I)$, which has been implicated in macrophage and $\mathrm{T}$ cell regulation (Sun et al., 2019). A complete list of candidate genes and their functions can be found in Supplemental Table S3.

The genome-wide association for milk SCS at 10-14 DIM, representing peak mastitis incidence, significantly associated SNPs at both novel and previously mapped QTL for mastitis traits (Figure 4c). A significantly associated SNP at BTA 3:89806231 overlaps with a QTL previously associated with SCS in a GWA using imputed SNP chip data in French Holsteins (Marete et al., 2018). The SNP significantly associated with SCS at 10-14 DIM at BTA 5:955228 and 6:111916870 have had no prior association with milk SCS, whereas the associated SNP at BTA 6:30947112 overlaps with QTL previously associated with both clinical mastitis and SCS (Klungland et al., 2001; Bennewitz et al., 2004; Michenet et al., 2016). Two large QTL were significantly associated on BTA 11, and while neither have been previously mapped for SCS or clinical mastitis, both overlap with previously mapped QTL for milk yield, which has a well-established relationship to mastitis, in a study of Danish Holsteins (Kucerová et al., 2006). The QTL at BTA29: 21528226-21543306 significantly associated with SCS at 10-14 DIM has not been associated with mastitis before, although it does overlap with a QTL previously mapped for milk yield. The identification of novel QTL for SCS during peak mastitis incidence (10-14 DIM) suggests that some genetic drivers of mastitis are not detected with deregressed breeding values or lactation averages. Perhaps only QTL not previously mapped for milk yield should be used in selection for mastitis resistance, given the multiple reports of positive genetic correlations between clinical mastitis and milk yield; more precise SCS phenotyping is required to make this distinction (Pösö and Mäntysaari, 1996; Heringstad et al., 1999; Hansen et al., 2002). It is probable that high milk yields contributed confounding bias to GWA results at 10-14 DIM, but individual milk yield records at our sampling time points were not available for inclusion in our GWA models.

To assess the genetics underlying milk SCC at the return to neutral or positive energy balance and the end of the voluntary breeding period, we performed GWA for SCS at 50-60 DIM and significantly associated a marker block at BTA 1: 65045803-65045168 that has not been previously mapped for mastitis-related traits (Figure 4d). Significantly associated QTL on BTA 3: 118976220-119034557 have not been previously mapped for mastitis-related traits but were associated with udder height and fore udder attachment, traits that were previously associated with increased odds of elevated SCC (Cole et al., 2011; Miles et al., 2019). A significantly associated SNP at BTA 4: 19709677 overlaps with QTL previously mapped for SCS in multiple studies, and one at BTA 26: 30956828 was previously mapped for both SCS and clinical mastitis (Zhang et al., 1998; Rupp and Boichard, 1999; Kühn et al., 2003; Longeri et al., 2006; Lund et al., 2008). We posit that examining SCS at this time point removes bias introduced in the phenotype by commonly observed nonpathogenic causes of inflammation in early lactation, such as lactogenesis, uterine involution, and negative energy balance. Furthermore, the confidence of the associations on BTA 4 and 26 were strongly validated, given their mapping in other independent studies. Candidate gene investigation revealed genes related to immune response signaling and hematopoietic cell differentiation (Supplemental Table S3; https://doi.org/10.3168/jds.2020-18322).

A GWA for SCS at 210-230 DIM, representing mid to late lactation and mid pregnancy, significantly associated SNP on BTA 4 at 22557323 and 118912645 (Figure 4f). Both of these SNP overlap with previously mapped QTL for both SCC and SCS (Zhang et al., 1998; Kühn et al., 2003; Longeri et al., 2006; Ibeagha-Awemu et al., 2016). A region located on BTA 5:1067453710679054 overlaps with previously mapped QTL for both SCS and clinical mastitis (Lund et al., 2008; Pimentel et al., 2011). We identified novel QTL at BTA 5:113340241-113358226, BTA 7:95730312-101060884, BTA 11:752355330-75240895, BTA 18:15929792, BTA 18:1700498-1901923, and BTA 23:14982097-15014257. A QTL on BTA 6:4761931-4920678 (Klungland et al., 2001), 2 significantly associated SNP on BTA 11: 66762518 and 68023914 (Schnabel et al., 2005), and SNP on BTAs 22 and 23 have previously been mapped for SCC (Schulman et al., 2004; Maltecca et al., 2011). An associated QTL on BTA 21 was previously mapped for clinical mastitis (Schulman et al., 2004; Elisa et al., 2015). By 210-230 DIM, the confounding physiological factors of parturition, lactogenesis, negative energy balance, and inflammation during early pregnancy have been removed and milk SCS may be a more accurate reflection of mastitis. The use of generalized milk SCC and lack of pathogenesis-specific phenotyping may explain the extremely polygenic nature of this trait and diverse arms of the immune system implicated through candidate gene investigation (Supplemental Table S3). Milk SCC with differential or microbial profiling would be required to refine the phenotype at this lactation stage and may result in more concentrated signals to specific genomic regions driving mammary immune response.

A GWA was performed for the traditional phenotype of lactation median SCS to provide a point of comparison for our lactation stage-specific analyses, and significantly associated SNP on 11 chromosomes 
spanning the genome (Figure $4 \mathrm{~g}$ ). Novel QTL were associated on BTA 2 and 4 , and nearby candidate genes included sphingomyelin phosphodiesterase acid like 3B (SMPDL3B), which has been shown to negatively regulate toll-like receptor (TLR) signaling and to influence macrophage membrane fluidity; thymocyte selection associated family member 2 (THEMIS2), which has been implicated in positive regulation of $\mathrm{B}$ cells and is believed to regulate macrophage TLR signaling; ficolin 3 (FCN3), a driver of the lectin complement pathway; and synaptotagmin like 1 (SYTL1), a mediator of neutrophil chemotaxis and granule exocytosis (Garred et al., 2009; Peirce et al., 2010; Heinz et al., 2015; Cheng et al., 2017; Ramadass et al., 2019). Significantly associated SNP on BTA 6 in a gene-scarce region were previously mapped for both SCS and clinical mastitis (Bennewitz et al., 2004; Sodeland et al., 2011). A significantly associated SNP at BTA 11:48421277 overlaps with a QTL previously mapped for SCS, and was positioned near genes encoding T-cell surface glycoprotein CD8 alpha and beta chains ( $C D 8 A$ and $C D 8 B)$, which are heavily involved in antigen presentation (Zhang et al., 1998; Parel and Chizzolini, 2004). A significantly associated QTL on BTA 15 was previously mapped for SCS, and nearby candidate genes include RAB39a member RAS oncogene family (RAB39A), which has been implicated in macrophage activation in response to LPS, and ATM serine/threonine kinase (ATM), which is involved in B-cell antigen receptor expression (Boichard et al., 2003; Rossi and Gaidano, 2012; Seto et al., 2013).

Both associated SNP on BTA 19 have been previously mapped for SCS in multiple studies, and candidate genes include interferon induced protein 35 (IFI35), a proinflammatory damage-associated molecular pattern released by activated macrophages in response to LPS; transmembrane protein 106A (TMEM106A), which has been shown to upregulate and polarize macrophages thereby inducing proinflammatory cytokine release; and CD300 molecule like family member G $(C D 300 L G)$, which is widely expressed on hematopoietic cells and involved in lymphocyte transmigration in inflamed tissues (Bennewitz et al., 2004; Tal-Stein et al., 2010; Cole et al., 2011; Umemoto et al., 2013; Dai et al., 2015; Xiahou et al., 2017). A novel QTL was associated on BTA 20:26074612-26079633 and associated SNP are located inside integrin subunit alpha 2 (ITGA2), which is thought to mediate inflammation by regulating immune cell adhesion (Adorno-Cruz and Liu, 2018). Two SNP on BTA 28 were significantly associated, one novel (BTA 28:19095996) and one near a previously mapped QTL for SCS in beef cattle at BTA 28:16086213 (Imumorin et al., 2011). There were no commonalities among the median SCS and lactation- stage GWA, suggesting that there are indeed different genetic mechanisms driving milk SCC at specific lactation stages.

The overall exploration of these genomic regions identified candidate genes implicated in multiple arms of the immune system, including TLR signaling, B-cell maturation, T-cell antigen presentation, and the complement pathway (Supplemental Table S3; https://doi.org/10 .3168/jds.2020-18322). The redundancy of the immune system has been well documented and is essential to maintaining robust host defenses to rapidly evolving pathogens (Casadevall and Pirofski, 2003; Fischer and Rausell, 2016). For example, transmembrane TLR4 and ficolin 3 of the complement pathway are part of unrelated pathways but both critical sentries of innate immunity that function to quickly recognize a wide range of pathogens and recruit innate and adaptive effector cells (Kumar et al., 2004; Hein et al., 2010). Similarly, $\mathrm{B}$ and $\mathrm{T}$ cells both rely on immunological memory to mount rapid and high-magnitude responses to previously encountered pathogens but do so through differing mechanisms (Murphy, 2012; Farber et al., 2016). These immunological pathways have a shared goal of pathogen destruction, and the redundancy in their goal acts as a safeguard against potential immune system malfunction. The identification of candidate genes in various redundant pathways suggests that cows that are highly susceptible to mastitis may be experiencing failures in multiple arms of the immune system.

\section{CONCLUSIONS}

A total of 48 QTL were identified via genome-wide association for SCS; of those, 27 were novel, having never been mapped for SCC or clinical mastitis previously. Numerous candidate genes relating to immunity were identified, and their function varied across multiple branches of the immune system, including stimulation of inflammatory cytokines, macrophage activation, B-cell maturation, T-cell recruitment, and the lectin pathway of the complement system. Redundancy is built into the immune system, and the identification of candidate genes belonging to different branches suggests that extremely mastitis susceptible cows may experience failures in multiple immune response mechanisms. We found that extremely susceptible cows (our "chronic" population) were genetically differentiated from others ("healthy" and "average" populations) and that this allelic differentiation could be localized to BTA 4, 6, and 7. We posit that variation in SCS across a lactation must be considered in genomic selection strategies, given the nonpathological causes of udder inflammation and the differing etiologies of mastitis. The wide range of significantly associated QTL and 
diversity of candidate gene functions suggest that selection based on phenotypes specific to lactation stage and pathogenesis, rather than generalized SCS, may lead to greater success in breeding mastitis-resistant cows.

\section{ACKNOWLEDGMENTS}

We thank commercial dairy farms for their invaluable participation, and many Cornell University graduate and undergraduate students associated with the Huson laboratory for their assistance with on farm sampling and laboratory work. Special thanks to Allison Herrick of Cornell University for her assistance in data compilation and Stephen Parry of the Cornell University Statistical Consulting Unit. This research project was funded by the US Department of Agriculture National Institute of Food and Agriculture (USDA/NIFA, Washington, DC) Federal Formula Funds Hatch Project NYC-127898. The authors have stated no conflicts of interest.

\section{REFERENCES}

Adorno-Cruz, V., and H. Liu. 2018. Regulation and functions of integrin alpha2 in cell adhesion and disease. Genes Dis. 6:16-24. https: //doi.org/10.1016/j.gendis.2018.12.003.

Akbar, H., T. M. Grala, M. Vailati Riboni, F. C. Cardoso, G. Verkerk, J. McGowan, K. Macdonald, J. Webster, K. Schutz, S. Meier, L. Matthews, J. R. Roche, and J. J. Loor. 2015. Body condition score at calving affects systemic and hepatic transcriptome indicators of inflammation and nutrient metabolism in grazing dairy cows. J. Dairy Sci. 98:1019-1032. https://doi.org/10.3168/jds.2014-8584.

Andersson, L. 2001. Genetic dissection of phenotypic diversity in farm animals. Nat. Rev. Genet. 2:130-138. https://doi.org/10.1038/ 35052563 .

Bennewitz, J., N. Reinsch, V. Guiard, S. Fritz, H. Thomsen, C. Looft, C. Kuhn, M. Schwerin, C. Weimann, G. Erhardt, F. Reinhardt, R. Reents, D. Boichard, and E. Kalm. 2004. Multiple quantitative trait loci mapping with cofactors and application of alternative variants of the false discovery rate in an enlarged granddaughter design. Genetics 168:1019-1027. https://doi.org/10.1534/genetics 104.030296.

Biffani, S., M. Del Corvo, R. Capoferri, A. Pedretti, M. Luini, J. L. Williams, G. Pagnacco, F. Minvielle, and G. Minozzi. 2017. An alternative experimental case-control design for genetic association studies on bovine mastitis. Animal 11:574-579. https://doi.org/10 $.1017 /$ S1751731116001750.

Bionaz, M., E. Trevisi, L. Calamari, F. Librandi, A. Ferrari, and G. Bertoni. 2007. Plasma paraoxonase, health, inflammatory conditions, and liver function in transition dairy cows. J. Dairy Sci. 90:1740-1750. https://doi.org/10.3168/jds.2006-445.

Boichard, D., C. Grohs, F. Bourgeois, F. Cerqueira, R. Faugeras, A. Neau, R. Rupp, Y. Amigues, M. Y. Boscher, and H. Leveziel. 2003. Detection of genes influencing economic traits in three French dairy cattle breeds. Genet. Sel. Evol. 35:77-101. https://doi.org/ 10.1186/1297-9686-35-1-77.

Cai, Z., B. Guldbrandtsen, M. S. Lund, and G. Sahana. 2018. Prioritizing candidate genes post-GWAS using multiple sources of data for mastitis resistance in dairy cattle. BMC Genomics 19:656. https://doi.org/10.1186/s12864-018-5050-x.

Casadevall, A., and L.-A. Pirofski. 2003. Exploiting the redundancy in the immune system: Vaccines can mediate protection by eliciting 'unnatural' immunity. J. Exp. Med. 197:1401-1404. https://doi .org/10.1084/jem.20030637.
Cheng, D., M. Deobagkar-Lele, E. Zvezdova, S. Choi, S. Uehara, D. Baup, S. C. Bennett, K. R. Bull, T. L. Crockford, H. Ferry, C. Warzecha, M. Marcellin, A. G. de Peredo, R. Lesourne, C. Anzilotti, P. E. Love, and R. J. Cornall. 2017. Themis2 lowers the threshold for B cell activation during positive selection. Nat. Immunol. 18:205-213. https://doi.org/10.1038/ni.3642.

Cole, J. B., G. R. Wiggans, L. Ma, T. S. Sonstegard, T. J. Lawlor Jr., B. A. Crooker, C. P. Van Tassell, J. Yang, S. Wang, L. K. Matukumalli, and Y. Da. 2011. Genome-wide association analysis of thirty one production, health, reproduction and body conformation traits in contemporary U.S. Holstein cows. BMC Genomics 12:408. https://doi.org/10.1186/1471-2164-12-408.

Council on Dairy Cattle Breeding. 2014. Description of National Genetic Evaluation Systems. Accessed Jan. 1, 2020. https://queries .uscdcb.com/reference/Form_GE_SCS_1412.pdf.

Dai, H., D. Xu, J. Su, J. Jang, and Y. Chen. 2015. Transmembrane protein 106a activates mouse peritoneal macrophages via the MAPK and NF-kappaB signaling pathways. Sci. Rep. 5:12461. https://doi.org/10.1038/srep12461.

Dohoo, I. R., and K. E. Leslie. 1991. Evaluation of changes in somatic cell counts as indicators of new intramammary infections. Prev. Vet. Med. 10:225-237. https://doi.org/10.1016/0167 $-5877(91) 90006-\mathrm{N}$.

Elisa, T., P. Antonio, P. Giuseppe, B. Alessandro, A. Giuseppe, C. Federico, D. Marzia, B. Ruggero, M. Giacomo, O. Andrea, R. Daniela, R. Mariaelisa, and L. Claudio. 2015. Endothelin receptors expressed by immune cells are involved in modulation of inflammation and in fibrosis: Relevance to the pathogenesis of systemic sclerosis. J. Immunol. Res. 2015:147616. https://doi.org/10.1155/ 2015/147616.

Fang, L., G. Sahana, G. Su, Y. Yu, S. Zhang, M. S. Lund, and P. Sørensen. 2017. Integrating sequence-based GWAS and RNA-Seq provides novel insights into the genetic basis of mastitis and milk production in dairy cattle. Sci. Rep. 7:45560. https://doi.org/10 $.1038 / \operatorname{srep} 45560$.

Farber, D. L., M. G. Netea, A. Radbruch, K. Rajewsky, and R. M. Zinkernagel. 2016. Immunological memory: Lessons from the past and a look to the future. Nat. Rev. Immunol. 16:124-128. https:// doi.org/10.1038/nri.2016.13.

Fischer, A., and A. Rausell. 2016. Primary immunodeficiencies suggest redundancy within the human immune system. Sci. Immunol. 1:eaah5861. https://doi.org/10.1126/sciimmunol.aah5861.

Forutan, M., S. Ansari Mahyari, C. Baes, N. Melzer, F. S. Schenkel, and M. Sargolzaei. 2018. Inbreeding and runs of homozygosity before and after genomic selection in North American Holstein cattle. BMC Genomics 19:98. https://doi.org/10.1186/s12864-018 $-4453-\mathrm{z}$.

Garred, P., C. Honore, Y. J. Ma, L. Munthe-Fog, and T. Hummelshoj. 2009. MBL2, FCN1, FCN2 and FCN3-The genes behind the initiation of the lectin pathway of complement. Mol. Immunol. 46:27372744. https://doi.org/10.1016/j.molimm.2009.05.005.

Graugnard, D. E., M. Bionaz, E. Trevisi, K. M. Moyes, J. L. SalakJohnson, R. L. Wallace, J. K. Drackley, G. Bertoni, and J. J. Loor. 2012. Blood immunometabolic indices and polymorphonuclear neutrophil function in peripartum dairy cows are altered by level of dietary energy prepartum. J. Dairy Sci. 95:1749-1758. https:// doi.org/10.3168/jds.2011-4579.

Hansen, M., M. S. Lund, M. K. Sorensen, and L. G. Christensen. 2002. Genetic parameters of dairy character, protein yield, clinical mastitis, and other diseases in the Danish Holstein cattle. J. Dairy Sci. 85:445-452. https://doi.org/10.3168/jds.S0022-0302(02)74093-9.

Hein, E., C. Honoré, M.-O. Skjoedt, L. Munthe-Fog, T. Hummelshøj, and P. Garred. 2010. Functional analysis of Ficolin-3 mediated complement activation. PLoS One 5:e15443. https://doi.org/10 .1371/journal.pone.0015443.

Heinz, L. X., C. L. Baumann, M. S. Koberlin, B. Snijder, R. Gawish, G. Shui, O. Sharif, I. M. Aspalter, A. C. Muller, R. K. Kandasamy, F. P. Breitwieser, A. Pichlmair, M. Bruckner, M. Rebsamen, S. Bluml, T. Karonitsch, A. Fauster, J. Colinge, K. L. Bennett, S. Knapp, M. R. Wenk, and G. Superti-Furga. 2015. The lipid-modifying enzyme SMPDL3B negatively regulates innate immunity. 
Cell Rep. 11:1919-1928. https://doi.org/10.1016/j.celrep.2015.05 .006 .

Heringstad, B., G. Klemetsdal, and J. Ruane. 1999. Clinical mastitis in Norwegian cattle: Frequency, variance components, and genetic correlation with protein yield. J. Dairy Sci. 82:1325-1330. https:/ /doi.org/10.3168/jds.S0022-0302(99)75356-7.

Ibeagha-Awemu, E. M., S. O. Peters, K. A. Akwanji, I. G. Imumorin, and X. Zhao. 2016. High density genome wide genotyping-bysequencing and association identifies common and low frequency SNPs, and novel candidate genes influencing cow milk traits. Sci. Rep. 6:31109. https://doi.org/10.1038/srep31109.

Imumorin, I. G., E. H. Kim, Y. M. Lee, D. J. De Koning, J. A. van Arendonk, M. De Donato, J. F. Taylor, and J. J. Kim. 2011. Genome scan for parent-of-origin QTL effects on bovine growth and carcass traits. Front. Genet. 2:44. https://doi.org/10.3389/fgene .2011 .00044 .

Japertiene, R., V. Juozaitiene, J. Kriauziene, J. Rudejeviene, and S. Japertas. 2007. The interrelationships between milkability traits and subclinical mastitis in cows. Pol. J. Vet. Sci. 10:255-261.

Kang, H. M., J. H. Sul, S. K. Service, N. A. Zaitlen, S.-Y. Kong, N. B. Freimer, C. Sabatti, and E. Eskin. 2010. Variance component model to account for sample structure in genome-wide association studies. Nat. Genet. 42:348-354. https://doi.org/10.1038/ng.548.

Klungland, H., A. Sabry, B. Heringstad, H. G. Olsen, L. Gomez-Raya, D. I. Vage, I. Olsaker, J. Odegard, G. Klemetsdal, N. Schulman, J. Vilkki, J. Ruane, M. Aasland, K. Ronningen, and S. Lien. 2001. Quantitative trait loci affecting clinical mastitis and somatic cell count in dairy cattle. Mamm. Genome 12:837-842. https://doi .org/10.1007/s00335001-2081-3.

Kucerová, J., M. S. Lund, P. Sorensen, G. Sahana, B. Guldbrandtsen, V. H. Nielsen, B. Thomsen, and C. Bendixen. 2006. Multitrait quantitative trait loci mapping for milk production traits in Danish Holstein cattle. J. Dairy Sci. 89:2245-2256. https://doi.org/10 .3168/jds.S0022-0302(06)72296-2.

Kühn, C., J. Bennewitz, N. Reinsch, N. Xu, H. Thomsen, C. Looft, G. A. Brockmann, M. Schwerin, C. Weimann, S. Hiendleder, G. Erhardt, I. Medjugorac, M. Forster, B. Brenig, F. Reinhardt, R. Reents, I. Russ, G. Averdunk, J. Blumel, and E. Kalm. 2003. Quantitative trait loci mapping of functional traits in the German Holstein cattle population. J. Dairy Sci. 86:360-368. https://doi .org/10.3168/jds.S0022-0302(03)73614-5.

Kumar, H., K. Takeda, and S. Akira. 2004. Toll-like receptors. Pages 190-194 in Encyclopedia of Biological Chemistry. W. J. Lennarz and M. D. Lane, ed. Elsevier, New York, NY.

Longeri, M., M. Polli, M. G. Strillacci, A. B. Samore, and M. Zanotti. 2006. Short communication: Quantitative trait loci affecting the somatic cell score on chromosomes 4 and 26 in Italian Holstein cattle. J. Dairy Sci. 89:3175-3177. https://doi.org/10.3168/jds .S0022-0302(06) 72591-7.

Lund, M. S., B. Guldbrandtsen, A. J. Buitenhuis, B. Thomsen, and C. Bendixen. 2008. Detection of quantitative trait loci in Danish Holstein cattle affecting clinical mastitis, somatic cell score, udder conformation traits, and assessment of associated effects on milk yield. J. Dairy Sci. 91:4028-4036. https://doi.org/10.3168/ jds.2007-0290.

Maltecca, C., K. A. Gray, K. A. Weigel, J. P. Cassady, and M. Ashwell. 2011. A genome-wide association study of direct gestation length in US Holstein and Italian Brown populations. Anim. Genet. 42:585-591. https://doi.org/10.1111/j.1365-2052.2011.02188.x.

Marete, A., G. Sahana, S. Fritz, R. Lefebvre, A. Barbat, M. S. Lund, B. Guldbrandtsen, and D. Boichard. 2018. Genome-wide association study for milking speed in French Holstein cows. J. Dairy Sci. 101:6205-6219. https://doi.org/10.3168/jds.2017-14067.

Martin-Urdiroz, M., M. J. Deeks, C. G. Horton, H. R. Dawe, and I. Jourdain. 2016. The exocyst complex in health and disease. Front. Cell Dev. Biol. 4:24. https://doi.org/10.3389/fcell.2016.00024.

McDermott, M. P., H. N. Erb, and R. P. Natzke. 1982. Predictability by somatic cell counts related to prevalence of intramammary infection within herds. J. Dairy Sci. 65:1535-1539. https://doi.org/ 10.3168/jds.S0022-0302(82)82378-3.
Mein, G., D. Reinemann, N. Schuring, and I. Ohnstad. 2004. Milking machines and mastitis risk: A storm in a teatcup. Proc. National Mastitis Council Annual Meeting, Charlotte, NC. National Mastitis Council, Verona, WI.

Michenet, A., M. Barbat, R. Saintilan, E. Venot, and F. Phocas. 2016. Detection of quantitative trait loci for maternal traits using highdensity genotypes of Blonde d'Aquitaine beef cattle. BMC Genet. 17:88. https://doi.org/10.1186/s12863-016-0397-y.

Miles, A. M., J. A. A. McArt, F. A. Leal Yepes, C. R. Stambuk, P. D. Virkler, and H. J. Huson. 2019. Udder and teat conformational risk factors for elevated somatic cell count and clinical mastitis in New York Holsteins. Prev. Vet. Med. 163:7-13. https://doi.org/10 .1016/j.prevetmed.2018.12.010.

Misztal, I. 2006. Challenges of application of marker assisted selection-A review. Anim. Sci. Pap. Rep. 24:5-10.

Murphy, K. P. 2012. Principles of innate and adaptive immunity. Pages 3-25 in Janeway's Immunobiology. 12th ed. Garland Science, New York, NY.

O'Leary, N. A., M. W. Wright, J. R. Brister, S. Ciufo, D. Haddad, R. McVeigh, B. Rajput, B. Robbertse, B. Smith-White, D. Ako-Adjei, A. Astashyn, A. Badretdin, Y. Bao, O. Blinkova, V. Brover, V. Chetvernin, J. Choi, E. Cox, O. Ermolaeva, C. M. Farrell, T. Goldfarb, T. Gupta, D. Haft, E. Hatcher, W. Hlavina, V. S. Joardar, V. K. Kodali, W. Li, D. Maglott, P. Masterson, K. M. McGarvey, M. R. Murphy, K. O’Neill, S. Pujar, S. H. Rangwala, D. Rausch, L. D. Riddick, C. Schoch, A. Shkeda, S. S. Storz, H. Sun, F. ThibaudNissen, I. Tolstoy, R. E. Tully, A. R. Vatsan, C. Wallin, D. Webb, W. Wu, M. J. Landrum, A. Kimchi, T. Tatusova, M. DiCuccio, P. Kitts, T. D. Murphy, and K. D. Pruitt. 2016. Reference sequence (RefSeq) database at NCBI: Current status, taxonomic expansion, and functional annotation. Nucleic Acids Res. 44(D1):D733-D745. https://doi.org/10.1093/nar/gkv1189.

Parel, Y., and C. Chizzolini. 2004. CD4+ CD8+ double positive (DP) $\mathrm{T}$ cells in health and disease. Autoimmun. Rev. 3:215-220. https:/ /doi.org/10.1016/j.autrev.2003.09.001.

Peirce, M. J., M. Brook, N. Morrice, R. Snelgrove, S. Begum, A. Lanfrancotti, C. Notley, T. Hussell, A. P. Cope, and R. Wait. 2010. Themis2/ICB1 is a signaling scaffold that selectively regulates macrophage Toll-like receptor signaling and cytokine production. PLoS One 5:e11465. https://doi.org/10.1371/journal.pone .0011465 .

Pimentel, E. C., S. Bauersachs, M. Tietze, H. Simianer, J. Tetens, G. Thaller, F. Reinhardt, E. Wolf, and S. Konig. 2011. Exploration of relationships between production and fertility traits in dairy cattle via association studies of SNPs within candidate genes derived by expression profiling. Anim. Genet. 42:251-262. https://doi.org/10 $.1111 / \mathrm{j} .1365-2052.2010 .02148 . x$.

Pösö, J., and E. A. Mäntysaari. 1996. Relationships between clinical mastitis, somatic cell score, and production for the first three lactations of Finnish Ayrshire. J. Dairy Sci. 79:1284-1291. https:// doi.org/10.3168/jds.S0022-0302(96)76483-4.

Purcell, S., B. Neale, K. Todd-Brown, L. Thomas, M. A. Ferreira, D. Bender, J. Maller, P. Sklar, P. I. de Bakker, M. J. Daly, and P. C. Sham. 2007. PLINK: A tool set for whole-genome association and population-based linkage analyses. Am. J. Hum. Genet. 81:559-575. https://doi.org/10.1086/519795.

R Core Team. 2019. R: A language and environment for statistical computing. R Foundation for Statistical Computing, Vienna, Austria. URL https://www.R-project.org.

Ramadass, M., J. L. Johnson, A. Marki, J. Zhang, D. Wolf, W. B. Kiosses, K. Pestonjamasp, K. Ley, and S. D. Catz. 2019. The trafficking protein JFC1 regulates Rac1-GTP localization at the uropod controlling neutrophil chemotaxis and in vivo migration. J. Leukoc. Biol. 105:1209-1224. https://doi.org/10.1002/JLB .1VMA0818-320R.

Rollin, E., K. C. Dhuyvetter, and M. W. Overton. 2015. The cost of clinical mastitis in the first 30 days of lactation: An economic modeling tool. Prev. Vet. Med. 122:257-264. https://doi.org/10.1016/j .prevetmed.2015.11.006. 
Rossi, D., and G. Gaidano. 2012. ATM and chronic lymphocytic leukemia: Mutations, and not only deletions, matter. Haematologica 97:5-8. https://doi.org/10.3324/haematol.2011.057109.

Rupp, R., and D. Boichard. 1999. Genetic parameters for clinical mastitis, somatic cell score, production, udder type traits, and milking ease in first lactation Holsteins. J. Dairy Sci. 82:2198-2204. https: //doi.org/10.3168/jds.S0022-0302(99)75465-2.

Schalm, O. W., and D. O. Noorlander. 1957. Experiments and observations leading to development of the California mastitis test. J. Am. Vet. Med. Assoc. 130:199-204.

Schepers, A. J., T. J. Lam, Y. H. Schukken, J. B. Wilmink, and W. J. Hanekamp. 1997. Estimation of variance components for somatic cell counts to determine thresholds for uninfected quarters. J. Dairy Sci. 80:1833-1840. https://doi.org/10.3168/jds.S0022 -0302(97)76118-6.

Schnabel, R. D., T. S. Sonstegard, J. F. Taylor, and M. S. Ashwell. 2005. Whole-genome scan to detect QTL for milk production, conformation, fertility and functional traits in two US Holstein families. Anim. Genet. 36:408-416. https://doi.org/10.1111/j.1365 $-2052.2005 .01337 . x$.

Schrooten, C., M. C. Bink, and H. Bovenhuis. 2004. Whole genome scan to detect chromosomal regions affecting multiple traits in dairy cattle. J. Dairy Sci. 87:3550-3560. https://doi.org/10.3168/ jds.S0022-0302(04)73492-X.

Schulman, N. F., S. M. Viitala, D. J. de Koning, J. Virta, A. MakiTanila, and J. H. Vilkki. 2004. Quantitative trait loci for health traits in Finnish Ayrshire cattle. J. Dairy Sci. 87:443-449. https:/ /doi.org/10.3168/jds.S0022-0302(04)73183-5.

Schutz, M. M. 1994. Genetic evaluation of somatic cell scores for United States dairy cattle. J. Dairy Sci. 77:2113-2129. https://doi.org/ 10.3168/jds.S0022-0302(94)77154-X.

Segura, V., B. J. Vilhjalmsson, A. Platt, A. Korte, U. Seren, Q. Long, and M. Nordborg. 2012. An efficient multi-locus mixed-model approach for genome-wide association studies in structured populations. Nat. Genet. 44:825-830. https://doi.org/10.1038/ng.2314.

Seto, S., K. Sugaya, K. Tsujimura, T. Nagata, T. Horii, and Y. Koide. 2013. Rab39a interacts with phosphatidylinositol 3-kinase and negatively regulates autophagy induced by lipopolysaccharide stimulation in macrophages. PLoS One 8:e83324. https://doi.org/ 10.1371/journal.pone.0083324.

SNP and Variation Suite. 2017. Mixed Linear Model Analysis. Accessed Mar. 18, 2020. https://doc.goldenhelix.com/SVS/latest/ svsmanual/mixedModelMethods/mlm_analysis.html.
Sodeland, M., M. P. Kent, H. G. Olsen, M. A. Opsal, M. Svendsen, E. Sehested, B. J. Hayes, and S. Lien. 2011. Quantitative trait loci for clinical mastitis on chromosomes 2, 6, 14 and 20 in Norwegian Red cattle. Anim. Genet. 42:457-465. https://doi.org/10.1111/j .1365-2052.2010.02165.x.

Soller, M. 1994. Marker assisted selection-An overview. Anim. Biotechnol. 5:193-207. https://doi.org/10.1080/10495399409525821.

Sun, S. W., L. Chen, M. Zhou, J. H. Wu, Z. J. Meng, H. L. Han, S. Y. Miao, C. C. Zhu, and X. Z. Xiong. 2019. BAMBI regulates macrophages inducing the differentiation of Treg through the TGF-beta pathway in chronic obstructive pulmonary disease. Respir. Res. 20:26. https://doi.org/10.1186/s12931-019-0988-z.

Tal-Stein, R., L. Fontanesi, M. Dolezal, E. Scotti, A. Bagnato, V. Russo, F. Canavesi, A. Friedmann, M. Soller, and E. Lipkin. 2010. A genome scan for quantitative trait loci affecting milk somatic cell score in Israeli and Italian Holstein cows by means of selective DNA pooling with single- and multiple-marker mapping. J. Dairy Sci. 93:4913-4927. https://doi.org/10.3168/jds.2010-3254.

Umemoto, E., A. Takeda, S. Jin, Z. Luo, N. Nakahogi, H. Hayasaka, C. M. Lee, T. Tanaka, and M. Miyasaka. 2013. Dynamic changes in endothelial cell adhesion molecule nepmucin/CD300LG expression under physiological and pathological conditions. PLoS One 8:e83681. https://doi.org/10.1371/journal.pone.0083681.

Weir, B. S., and C. C. Cockerham. 1984. Estimating F-statistics for the analysis of population structure. Evolution 38:1358-1370. https://doi.org/10.1111/j.1558-5646.1984.tb05657.x.

Xiahou, Z., X. Wang, J. Shen, X. Zhu, F. Xu, R. Hu, D. Guo, H. Li, Y. Tian, Y. Liu, and H. Liang. 2017. NMI and IFP35 serve as proinflammatory DAMPs during cellular infection and injury. Nat. Commun. 8:950. https://doi.org/10.1038/s41467-017-00930-9.

Zhang, Q., D. Boichard, I. Hoeschele, C. Ernst, A. Eggen, B. Murkve, M. Pfister-Genskow, L. A. Witte, F. E. Grignola, P. Uimari, G. Thaller, and M. D. Bishop. 1998. Mapping quantitative trait loci for milk production and health of dairy cattle in a large outbred pedigree. Genetics 149:1959-1973.

\section{ORCIDS}

Asha M. Miles @ https://orcid.org/0000-0003-2175-7910 Heather J. Huson @ \. https://orcid.org/0000-0001-8299-0447 